\title{
Whole Genome Sequencing Reveals a Chromosome 9p Deletion Causing DOCK8 Deficiency in an Adult Diagnosed with Hyper IgE Syndrome Who Developed Progressive Multifocal Leukoencephalopathy
}

\author{
Aaron G. Day-Williams • Chao Sun • Ilijas Jelcic • \\ Helen McLaughlin • Tim Harris • Roland Martin • \\ John P. Carulli
}

Received: 19 June 2014 / Accepted: 23 October 2014 /Published online: 12 November 2014

(C) The Author(s) 2014. This article is published with open access at Springerlink.com

\begin{abstract}
Purpose A 30 year-old man with a history of recurrent skin infections as well as elevated serum IgE and eosinophils developed neurological symptoms and had T2-hyperintense lesions observed in cerebral MRI. The immune symptoms were attributed to Hyper IgE syndrome (HIES) and the neurological symptoms with presence of JC virus in cerebrospinal fluid were diagnosed as Progressive Multifocal Leukoencephalopathy (PML). The patient was negative for STAT3 mutations. To determine if other mutations explain HIES and/or PML in this subject, his DNA was analyzed by whole genome sequencing.

Methods Whole genome sequencing was completed to $30 \mathrm{X}$ coverage, and whole genome SNP typing was used to complement these data. The methods revealed single nucleotide variants, structural variants, and copy number variants across the genome. Genome-wide data were analyzed for homozygous or compound heterozygous null mutations for all protein coding genes. Mutations were confirmed by PCR and/or Sanger sequencing.
\end{abstract}

Aaron Day-Williams, Chao Sun and Ilijas Jelcic have contributed equally to this paper.

Electronic supplementary material The online version of this article (doi:10.1007/s10875-014-0114-4) contains supplementary material, which is available to authorized users.

A. G. Day-Williams • C. Sun • H. McLaughlin • T. Harris •

J. P. Carulli $(\triangle)$

Translational Sciences, Biogen Idec, Cambridge, MA, USA

e-mail: john.carulli@biogenidec.com

I. Jelcic $\cdot$ R. Martin

Department of Neurology, University Hospital Zurich, Zurich,

Switzerland
Results Whole genome analysis revealed deletions near the telomere of both copies of chromosome 9p. Several genes, including DOCK8, were impacted by the deletions but it was unclear whether each chromosome had identical or distinct deletions. PCR across the impacted region combined with Sanger sequencing of selected fragments confirmed a homozygous deletion from position 10,211 to 586,751 .

Conclusion While several genes are impacted by the deletion, DOCK8 deficiency is the most probable cause of HIES in this patient. DOCK8 deficiency may have also predisposed the patient to develop PML.

Keywords Hyper IgE Syndrome · DOCK8 deficiency · primary immune deficiency $\cdot$ Progressive Multifocal Leukoencephalopathy (PML) $\cdot$ JC virus

The hyper IgE syndromes (HIES) are rare primary immunodeficiencies characterized by elevated serum $\mathrm{IgE}$, dermatitis and recurrent skin and lung infections $[1,2]$. There are two forms of HIES that are characterized based on their inheritance patterns: autosomal-dominant HIES (AD-HIES) and autosomal-recessive HIES (AR-HIES). AD-HIES is caused by dominant mutations in STAT3 and is characterized in addition to the symptoms noted above by extra-immune manifestations including skeletal, connective tissue and vasculature abnormalities [1,2]. AR-HIES is caused by homozygous or compound heterozygous mutations in DOCK8, TYK2 or STK3, and these patients do not possess any of the extraimmune manifestations found in AD-HIES [3-6]. The major manifestations of DOCK 8 deficiency leading to AR-HIES are recurrent viral and bacterial infections starting early in life, extreme eosinophilia, and elevated IgE levels. The causes of DOCK8 deficiency thus far described range from point 
mutations and small indels to large deletions of portions of DOCK8 preventing expression of the protein [3-6]. This report adds to the growing body of knowledge about DOCK8-deficient AR-HIES and discovers the largest published deletion in the region around DOCK8. In addition, we add to the literature showing the occurence of Progressive Multifocal Leukoencephalopathy in DOCK8 deficient individuals.

A 30 year old, male, Caucasian patient suffering from eczematoid dermatitis developed impetiginization of the skin with Klebsiella pneumonia and group A $\beta$-hemolytic streptococcus species in July, 2008. The patient was diagnosed with HIES based on elevated serum $\operatorname{IgE}(26,800 \mathrm{kU} / \mathrm{L})$ and elevated eosinophils $\left(1.6 \times 10^{9} / \mathrm{L}\right)$. The patient had atopic dermatitis that was treated with topical corticosteroids and recurrent herpesviral skin infections from the age of 6 years. There were no reports of any other immunosuppressive agents. The patient history revealed that his parents were first cousins, however, no immunological diseases, opportunistic infection or childhood diseases were reported in the parent's siblings or their children. In September, 2008 the patient developed a leftsided sensory hemisyndrome, which progressed to a spasticatactic hemiparesis within a few weeks. A cerebral MRI showed a large confluent T2-hyperintense lesion in the frontal parietal central region of the right cerebral hemisphere, a small T2-hyperintense lesion in the right temporal cortex, and small T2-hyperintense lesions in the right cerebellar heimisphere. In
October, 2008 the cerebrospinal fluid (CSF) of the patient was positive for JC polyoma virus DNA (500 copies $/ \mathrm{mL}$ ) leading to the diagnosis of Progressive Multifocal Leukoencephalopathy (PML). Peripheral blood analysis showed repeatedly highly increased numbers of $\operatorname{IgE}$ $(12,166-26,800 \mathrm{kU} / \mathrm{l})$ and eosinophils $(3,066-6,068 / \mathrm{ul})$ and decreased levels of lymphocytes (296-770/ul), CD3+ T cells (130-265/ul), CD4+ T cells (71-169/ul), CD8+ T cells (29109/ul), CD19+ B cells (173-262/ul) and NK cells (10-81/ul) (Table S1). After stimulation of lymphocytes with phytohemagglutinin, $\mathrm{CD} 3+\mathrm{T}$ cells responded adequately as shown by intracellular production of interferon- $\gamma$ ( $24 \%$ of cells), interleukin-2 $(25.6 \%)$ and tumor necrosis factor- $\alpha(11.2 \%)$.

A screen for STAT3 mutations in April, 2009 was negative. The family history of first cousin parents and the absence of STAT3 mutations lead to the refined diagnosis of AR-HIES of unknown etiology. In August 2009, antiepileptic treatment with $3,000 \mathrm{mg}$ levetiracetam and $100 \mathrm{mg}$ pregabaline daily was started because of focal sensory epileptic seizures in the left hemibody. MRI follow-up showed a reduced size of the T2-lesion within the right cerebral central region, but CSF JCV DNA copy number had increased tenfold $(5,200 \mathrm{JCV}$ genomic copies $/ \mathrm{mL}$ ). Until December 2010, neurological deficits had progressed only mildly, but MRI showed dissemination and enlargement of the PML lesions in the left thalamic region, left hemisphere, pons, and the right cerebellar pedunculus. The patient's DNA was sent for whole-genome
Fig. 1 Deletion of DOCK8 in a patient with HIES and PML. $A$. Telomeric region of chromosome $9 \mathrm{p}$ showing the deleted region and the impacted genes. $B$.

Hypothetical ploidy observed in whole genome sequence. Note apparent single copy coverage near the telomere, then nearly $500 \mathrm{~kb}$ with no coverage, and then diploid coverage starting at approximately 586,000 bases. The letters $a, b, c$ and $d$ show the approximate location of PCR primers used to confirm the nature of the deletion. $C$. Results of PCR using the primers shown in $1 \mathrm{~B}$. Gel a: lanes 1,2 , and 4 are controls, lane 3 is the HIES subject. Gels b, c and d: lane 1 is the HIES subject, lanes 2 and 3 are control subject, lane 4 is a no template control. Primer sets $\mathrm{a}, \mathrm{b}$, and $\mathrm{c}$ produce bands from the controls but not from the HIES subject, and primer set $\mathrm{d}$ only produces a band from the HIES subject

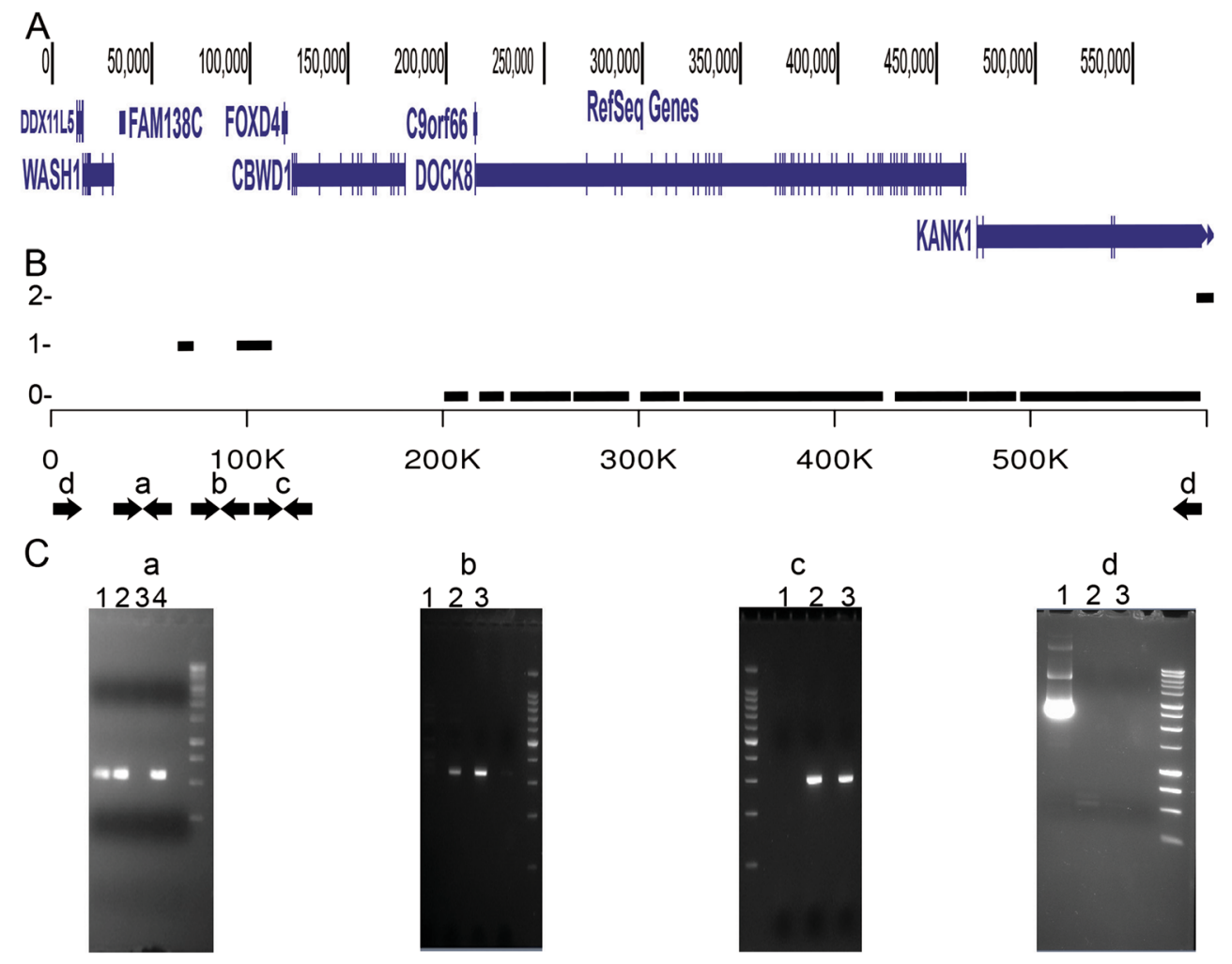


SNP analysis and sequencing in April, 2012. After this the patient was not available for follow-up of the disease course.

The patient's DNA was whole genome sequenced (WGS) by Complete Genomics Incorporated (CGI; software version 2.0) $[7,8]$ and was analyzed on the Illumina Omni 1 quad genome-wide SNP array. The WGS approach used short (3135 base) sequence reads at $>30 \mathrm{X}$ coverage mapped to the reference genome using methods previously described [7] to identify single nucleotide, copy number, and structural variants. Relative to the reference genome, the sequence of this individual included 19435 missense variants, 178 nonsense variants, 470 frameshift variants, and $>100$ copy number and structural variants. Single nucleotide variants $(\mathrm{SNVs})$ were analyzed using the ENSEMBL Variant Effect Predictor v2.8 [9] on the ENSEMBL v70 database, and variant effects on the annotated canonical transcripts for all genes were assessed via PolyPhen2 [10] and SIFT [11]. A variant was considered possibly damaging if it was determined to be either 'probably damaging' or 'possibly damaging' by PolyPhen2 or 'deleterious' by SIFT. We examined known genes associated with immune deficiency, including the HIES genes STAT3, TYK2, STK3 and DOCK8, and observed no damaging mutations in STAT3 or STK3, heterozygosity for a possibly damaging missense variant in TYK2 (rs147991080, R448W, MAF $<0.01$ (http://browser.1000genomes.org/); Table S2), and large deletions on both copies of chromosome $9 p$ in the region that includes DOCK8. The SNP array data also suggested a large deletion on chromosome $9 p$, with mostly non-called SNPs from approximately 194,000 to 600,000 bases (Table S3). Given the heterozygosity and ambiguous function of the TYK2 variant and the obvious deletions around DOCK8, it is clear that the DOCK8 mutation(s) contribute to the patient's disease.

The WGS and SNP data were not clear on the exact deletion breakpoints or whether the patient was homozygous for the same deletion or had inherited two different deletions.

Table 1 Genes in the deleted interval on chromosome 9, with Gene Ontology $(\mathrm{GO} ;([24,25])$ biological process and function annotation, as well as associated phenotypes in Online Medelian Inheritance in Man (OMIM; http://omim.org/)

\begin{tabular}{|c|c|c|c|}
\hline Gene Symbol & GO biological process & GO function & $\begin{array}{l}\text { OMIM phenotypes } \\
\text { (MIM number) }\end{array}$ \\
\hline DDX11L5 & None & None & None \\
\hline WASH1 & $\begin{array}{l}\text { GO:0006810:transport } \\
\text { GO:0016197:endosomal } \\
\text { transport } \\
\text { GO:0034314:Arp2/3 } \\
\text { complex-mediated actin nucleation } \\
\text { GO:0042147:retrograde } \\
\text { transport, endosome to Golgi }\end{array}$ & $\begin{array}{l}\text { GO:0003779:actin binding } \\
\text { GO:0005515:protein binding } \\
\text { GO:0031625:ubiquitin protein } \\
\text { ligase binding } \\
\text { GO:0043014:alpha-tubulin } \\
\text { binding }\end{array}$ & None \\
\hline FAM138C & None & None & None \\
\hline FOXD4 & $\begin{array}{l}\text { GO:0006351:transcription, } \\
\text { DNA-templated } \\
\text { GO:0006355:regulation of transcription, } \\
\text { DNA-templated }\end{array}$ & $\begin{array}{l}\text { GO:0003677:DNA } \\
\text { binding } \\
\text { GO:0003700:sequence-specific } \\
\text { DNA binding transcription factor } \\
\text { activity } \\
\text { GO:0008301:DNA binding, bending } \\
\text { GO:0043565:sequence-specific } \\
\text { DNA binding }\end{array}$ & None \\
\hline CBWD1 & None & $\begin{array}{l}\text { GO:0000166:nucleotide binding } \\
\text { GO:0005524:ATP binding }\end{array}$ & None \\
\hline C9orf166 & None & None & None \\
\hline Dock8 & $\begin{array}{l}\text { GO:0001771;immunological synapse } \\
\text { formation } \\
\text { GO:0007264;small GTPase mediated } \\
\text { signal transduction } \\
\text { GO:0007596:blood coagulation } \\
\text { GO:0036336:dendritic cell } \\
\text { migration } \\
\text { GO:0043547:positive regulation of } \\
\text { GTPase activity } \\
\text { GO:0061485:memory T cell proliferation } \\
\text { GO:0070233:negative regulation } \\
\text { of T cell apoptotic process }\end{array}$ & $\begin{array}{l}\text { GO:0005085:guanyl-nucleotide } \\
\text { exchange factor activity } \\
\text { GO:0005515:protein binding }\end{array}$ & $\begin{array}{l}\text { Hyperimmunoglobulin E } \\
\text { recurrent infection syndrome, } \\
\text { autosomal recessive (243700) } \\
\text { Mental retardation, autosomal } \\
\text { dominant } 2 \text { (614113) }\end{array}$ \\
\hline KANK1 & None & None & $\begin{array}{l}\text { Cerebral palsy, spastic } \\
\text { quadriplegic, } 2 \text { (612900) }\end{array}$ \\
\hline
\end{tabular}


The WGS CNV analysis estimated that the patient was homozygous null for DOCK8 and some of KANK1, but could be hemizygous towards the telomere encompassing CBWD1, FOXD4, FAM138C, WASH1, and DDX11L5 (Fig. 1 panels $\mathrm{A}, \mathrm{B})$, and was consistent with the hypothesis that the patient had some DNA telomeric to DOCK8. The WGS analysis of the p-arm from the telomere to the DOCK8 locus is complicated by a segmental duplication that results in extremely high sequence similarity to Chromosome $2[12,13]$ and ambiguous sequence assembly. To resolve the breakpoints for the individual's deletion(s) we designed targeted PCR around SNPs rs 12353065 , rs 7853676 and rs 11794423 which the WGS SNP analysis called high confidence SNPs, the WGS CNV analysis estimated to be hemizygous, and PCR primers unique to chromosome 9 could be designed (Fig. 1 panels B,C). Figure 1 panel $C$ shows that the PCR with primers for the 3 SNPs (gels $\mathrm{a}, \mathrm{b}$ and $\mathrm{c}$ ) are all negative illustrating that the patient is in fact homozygous null from around the telomere into KANK1. To resolve the exact breakpoints we designed PCR primers close to the telomere and in KANK1 (PCR pair d Fig. 1 panel B,C). Upon the successful amplification of this fragment we cloned the DNA and Sanger sequenced the fragment. We performed a global gapped alignment with the Needleman-Wunsch algorithm of the resulting DNA fragment to chromosome 9 from bases 1-700,000 (NC_000009.11) and it revealed the alignment in Supplementary Figure 1. The alignment shows a massive homozygous deletion from position 10,211 to 586,751 that makes the patient homozygous null for the genes WASH1, FAM138C, FOXD4, CWBD1, C9orf66, DOCK8 and most of KANK1.

DOCK8 deficiency is the most likely cause of HIES in this subject, and may have predisposed him to the development of PML. Among the genes in the deletion interval none of the other genes are so obviously connected to the phenotype (Table 1), and elsewhere in the genome there are no mutations consistent with known inheritance patterns for HIES. Notably, this is not the first case report of PML in DOCK8 deficiency [14]. PML has been observed in a limited subset of PIDs that includes DOCK8 deficiency, Wiskott-Aldrich Syndrome, STAT1 gain of function mutations and CD40L deficiency [15-20]. This observation highlights a new pathway by which the ubiquitous JC virus causes PML in a small fraction of individuals and further demonstrates the utility of whole genome sequencing for diagnosing diseases of unknown etiology. DOCK 8 deficiency can be treated by bone marrow transplantation [21-23], and the possibility of PML in these individuals is a reason to consider early and accurate diagnosis of suspect cases by genetic analysis and treatment by transplantation.

Acknowledgments The authors would like to thank the patient and his family for participation in the study. We thank Susan Goelz, Tatiana Plavina, and Gabrielle Glick for intellectual input and operational support. This study was approved by the appropriate ethics committee and has been performed in accordance with the 1964 Declaration of Helsinki and its later amendments.

Open Access This article is distributed under the terms of the Creative Commons Attribution License which permits any use, distribution, and reproduction in any medium, provided the original author(s) and the source are credited.

\section{References}

1. Freeman AF, Holland SM. The hyper-IgE syndromes. Immunol Allergy Clin N Am. 2008;28(2):277-91.

2. Freeman AF, Holland SM. Clinical manifestations of hyper $\operatorname{IgE}$ syndromes. Dis Markers. 2010;29(3-4):123-30.

3. Engelhardt KR, McGhee S, Winkler S, Sassi A, Woellner C, LopezHerrera $\mathrm{G}$, et al. Large deletions and point mutations involving the dedicator of cytokinesis 8 (DOCK8) in the autosomal-recessive form of hyperIgE syndrome. J Allergy Clin Immunol. 2009;124(6):1289-302 e4.

4. Sanal O, Jing H, Ozgur T, Ayvaz D, Strauss-Albee DM, Ersoy-Evans $\mathrm{S}$, et al. Additional diverse findings expand the clinical presentation of DOCK8 deficiency. J Clin Immunol. 2012;32(4):698-708.

5. Su HC. Dedicator of cytokinesis 8 (DOCK8) deficiency. Curr Opin Allergy Clin Immunol. 2010;10(6):515-20.

6. Zhang Q, Davis JC, Lamborn IT, Freeman AF, Jing H, Favreau AJ, et al. Combined immunodeficiency associated with DOCK8 mutations. N Engl J Med. 2009;361(21):2046-55.

7. Carnevali P, Baccash J, Halpern AL, Nazarenko I, Nilsen GB, Pant $\mathrm{KP}$, et al. Computational techniques for human genome resequencing using mated gapped reads. J Comput Biol J Comput Mol Cell Biol. 2012;19(3):279-92.

8. Drmanac R, Sparks AB, Callow MJ, Halpern AL, Burns NL, Kermani BG, et al. Human genome sequencing using unchained base reads on self-assembling DNA nanoarrays. Science. 2010;327(5961):78-81.

9. McLaren W, Pritchard B, Rios D, Chen Y, Flicek P, Cunningham F. Deriving the consequences of genomic variants with the Ensembl API and SNP Effect Predictor. Bioinformatics. 2010;26(16):2069-70.

10. Adzhubei I, Jordan DM, Sunyaev SR. Predicting functional effect of human missense mutations using PolyPhen-2. Current protocols in human genetics / editorial board, Jonathan L Haines [et al.]. 2013; Chapter 7:Unit7 20.

11. Kumar P, Henikoff S, Ng PC. Predicting the effects of coding nonsynonymous variants on protein function using the SIFT algorithm. Nat Protoc. 2009;4(7):1073-81.

12. Fan Y, Newman T, Linardopoulou E, Trask BJ. Gene content and function of the ancestral chromosome fusion site in human chromosome 2 q13-2q14.1 and paralogous regions. Genome Res. 2002;12(11):1663-72.

13. Wong A, Vallender EJ, Heretis K, Ilkin Y, Lahn BT, Martin CL, et al. Diverse fates of paralogs following segmental duplication of telomeric genes. Genomics. 2004;84(2):239-47.

14. Dellepiane RM, Engelhardt K, Pfeifer D, Beilis L, Raimondi M, Pavesi P, et al., editor. Hyper IgE syndrome: fatal progressive multifocal leukoencephalopathy in an Italian child with DOCK8 mutation. Meeting of the European Society for Immunodeficiencies; 2010; Istanbul.

15. Aschermann Z, Gomori E, Kovacs GG, Pal E, Simon G, Komoly S, et al. X-linked hyper-IgM syndrome associated with a rapid course of multifocal leukoencephalopathy. Arch Neurol. 2007;64(2):273-6.

16. Durandy A, Kracker S, Fischer A. Primary antibody deficiencies. Nat Rev Immunol. 2013;13(7):519-33. 
17. Katz DA, Berger JR, Hamilton B, Major EO, Post MJ. Progressive multifocal leukoencephalopathy complicating Wiskott-Aldrich syndrome. Report of a case and review of the literature of progressive multifocal leukoencephalopathy with other inherited immunodeficiency states. Arch Neurol. 1994;51(4):422-6.

18. McGhee SA, Chatila TA. DOCK 8 immune deficiency as a model for primary cytoskeletal dysfunction. Dis Markers. 2010;29(3-4):151-6.

19. Randall KL, Lambe T, Johnson AL, Treanor B, Kucharska E, Domaschenz H, et al. Dock8 mutations cripple B cell immunological synapses, germinal centers and long-lived antibody production. Nat Immunol. 2009;10(12):1283-91.

20. Sampaio EP, Hsu AP, Pechacek J, Bax HI, Dias DL, Paulson ML, et al. Signal transducer and activator of transcription 1 (STAT1) gainof-function mutations and disseminated coccidioidomycosis and histoplasmosis. J Allergy Clin Immunol. 2013;131(6):1624-34.

21. McDonald DR, Massaad MJ, Johnston A, Keles S, Chatila T, Geha RS, et al. Successful engraftment of donor marrow after allogeneic hematopoietic cell transplantation in autosomal-recessive hyper-IgE syndrome caused by dedicator of cytokinesis 8 deficiency. J Allergy Clin Immunol. 2010;126(6):1304-5 e3.

22. Metin A, Tavil B, Azik F, Azkur D, Ok-Bozkaya I, Kocabas C, et al. Successful bone marrow transplantation for DOCK8 deficient hyper IgE syndrome. Pediatr Transplant. 2012;16(4): 398-9.

23. Barlogis V, Galambrun C, Chambost H, Lamoureux-Toth S, Petit P, Stephan JL, et al. Successful allogeneic hematopoietic stem cell transplantation for DOCK8 deficiency. J Allergy Clin Immunol. 2011;128(2):420-22 e2.

24. Binns D, Dimmer E, Huntley R, Barrell D, O’Donovan C, Apweiler R. QuickGO: a web-based tool for Gene Ontology searching. Bioinformatics. 2009;25(22):3045-6.

25. Dimmer EC, Huntley RP, Alam-Faruque Y, Sawford T, O'Donovan C, Martin MJ, et al. The UniProt-GO Annotation database in 2011. Nucleic Acids Res. 2012;40(Database issue):D565-70. 